\title{
Exploration and Practice of vocational practical P. E. teaching mode in higher vocational college
}

\author{
Weiguo $\mathrm{LI}^{1, \mathrm{a}}$, ke FENG ${ }^{2, \mathrm{~b},{ }^{*}}$ and Jun REN ${ }^{3, \mathrm{c}}$ \\ ${ }^{1,2}$,Hebei Women's Vocational College, Shijiazhuang, He Bei, China \\ ${ }^{3}$ Shijiazhuang City, Long Street Primary School,Shijiazhuang, He Bei, China \\ aLweiguo2005@163.com, ${ }^{\mathrm{b}}$ Fengke18203119799@163.com, ${ }^{\mathrm{C}}$ r4407994@126.com
}

\begin{abstract}
P. E. teaching mode in higher vocational college has caused widespread concern in the sports world.Construction of vocational practical P. E. teaching mode should adhere to the four principles, namely the principle of health, practical principles, compensatory principle and the principle of lifelong. At the same time, we should focus on four areas, namely, curriculum, open content, teaching methods and evaluation aspects methods.
\end{abstract}

Keywords. Higher Vocational College, Vocational Practical P. E. , Teaching Mode

\section{高职院校职业实用性体育教学模式的探索与实践}

\author{
李卫国 ${ }^{1, a}$, 冯 科, b, * 任 筠 ${ }^{3, c}$ \\ 1,2 , 河北女子职业技术学院, 石家庄, 河北, 中国 \\ 3, 石家庄市长征街小学, 石家庄, 河北, 中国 \\ aLweiguo2005@163.com, b Fengke18203119799@163.com, cr4407994@126.com
}

中文摘要. 高职院校职业实用性体育教学模式 已经引起了体育界的广泛关注。构建职业实用性体 育教学模式应该坚持四项原则, 即健康性原则、实 用性原则、补偿性原则与终身性原则; 着眼于四个 方面, 即课程体系、开设内容、授课方式和评价方 式等方面。

关键词: 高职院校 职业实用性体育 教学模式

\section{1. 引言}

职业实用性体育教学已经引起了体育 界的广泛瞩目。许多高职院校都在积极探索 符合自己职业院校的职业实用性体育教学 模式, 以期在改革的浪潮中脱颖而出, 并占 有一席之地。

\section{2. 职业实用性体育教学模式提出的现实价} 值

所谓职业实用性体育教学是指要“根据 学生未来将要从事的职业特点及职业对身 体素质的特殊需求, 重点选择能提高职业特 殊身体素质和职业技能的课程内容, 以有效
发挥职业实用性体育为未来职业与生产劳 动服务的作用。” ${ }^{[1]}$ 实施职业实用性体育教 学对于高职院校及学生等具有着十分重要 的现实意义。

\section{1 现代化大生产要求实施职业实用性体 育教学模式}

计算机与多媒体等科学技术的突飞猛 进, 使人类的生产工具不断更新, 它影响着 我们生活的方方面面, 反应在体力劳动与脑 力劳动的关系上, 主要体现在以下两方面: 一方面体力劳动与脑力劳动的结构比例正 在发生着深刻变化, 一一体力劳动者的数量 急剧下降, 脑力劳动者的数量不断上升。比 例的变化, “对脑力劳动者的操作技能以及 适应性与灵活性提出了更高要求, 尤其是手 脚协调能力、反应判断能力以及感官系统 与运, 动系统协同能力, 已成为各种职业的 必备职业能力。” ${ }^{[2]}$ 另一方面体力劳动与脑 力劳动的融合性日趋加大, 并有一体化的倾 向, 即在许多工作岗位中, 体力劳动与脑力 
劳动业已无法彻底彼此分离, “它们你中有 我, 我中有你”。如护理专业、营销专业、 商贸专业、机械专业与公安专业等等, 它们 不仅需要脑力劳动, 还需要一定的体力劳动 与之相匹配, 需要承受一定的职业运动负 荷, 只不过是有的工作岗位对手指的灵活度 要求较高, 有的工作岗位对腿脚的灵活度要 求较高等等而已。社会现代化大生产要求高 职院校重视实用性体育教学模式, 不可在再 产、建设、管 “象牙塔” 中孤芳自赏。

\section{2 高职特色定位要求实施职业实用性体 育教学模式}

培养面向生理与服务一线高级技能型 人才的特色定位决定了高职院校的教学必 须与普通高校的教学有所区分, 体育教学作 为高职教学的重要组成部分, 亦概莫能外。 也就是说高职院校体育教学除了应该具有 健康属性之外, 还应该具有职业实用性, 即 针对现实的生产要求、现实的建设要求、现 实的管理要求、现实的服务要求, 充分 “利 用体育锻炼为载体, 使身体健康的同时, 着 重发展学生未来将从事的职业所需的身心 素质和相关体能, 提高职业素质和体能, 以 增强学生的竞争力, 形成以专业培养目 标 为依据的高职体育职业体能课程体系” ${ }^{[3]}$, 不能再照抄普通体育课教学大纲要求, 照搬 普通高校教学的内容与形式, 进行简单的课 程体系整合, 泛泛的实施一般身体素质训 练。

\section{3 发展特殊素质要求实施职业实用性体 育教学模式}

为了更好地掌握或精通某项专业技能, 劳动者除了需要在具备全面发展的一般素 质之外, 还需要具备与自己未来岗位职业相 匹配的身体素质, 这种身体素质即特殊素 质。有研究表明: 虽然健全的体魄是特殊素 质的基础, 但 “一般身体素质水平的高低与 顺利适应职业需要和提高劳动生产率之间 并不存在直线相关关系。” ${ }^{[4]}$ 即经常进行体 育锻炼, 机体各器官系统功能较好, 身体素 质不错的劳动者, 与其职业的能力和岗位要 求未必成正比。这就要求高职院的体育教学 应该从自身的专业培养目标出发, 注重发展 学生的特色身体素质, 探索实施职业实用性
体育教学模式。此外, 还应该注意到一旦学 生岗前身体素质训练水平不高, 即不具备工 作岗位需要的特殊身体素质, 很有可能导致 学生离职率上升, 工作效率低下, 甚至会出 现一些工伤致残事件。所以加强学生的特殊 素质训练, 实施职业实用性体育教学模式, 对于高职院校的体育教学来说具有非常重 要的现实意义。

\section{3. 职业实用性体育教学模式构建的基本原 则}

任何模式的建构都不会凭空臆造, 空穴 来风, 它必然遵循一定的原则, 高职院校职 业实用性体育教学模式的构建也是如此。

\section{1 “健康” 是职业实用性体育教学模式 构建的前提}

健康性是任何体育教学模式构建都无 法规避的前提与基础, 职业实用性体育教学 模式作为体育教学模式的一种, 自然也包含 于其中。构建职业实用性体育教学模式的健 康性原则主要集中体现于一点即必须立足 于学生自身当前具有的运动技能水平。这对 我们教学提出了以下几点要求: 一是教学内 容的选取应该遵循适中原则。“适中” 是指 既不能揠苗助长, 脱离学生运动技能的实际 水平, 选择那些难度较大水平较高的动作技 术, 也不能因为 “怕出事”, 对学生不作要 求, 或者过低要求, 实行 “放羊式管理”, 使学生达不到体育训练的效果。二是体育运 动量的控制应该遵循合理性原则。高校学生 身体素的每况愈下已经成为不争的事实, 且 参次不齐, 差异较大。因此, 我们在进行体 育训练时应该控制好时间与度, 同事还要因 部位而异, 即具有选择性和针对性。例如对 于一些较长时间不进行屈缩的身体部位应 该选择伸展性训练。此外, 还要注意, 在进 行强度较高的训练之后应该进行适度合理 的静力牵拉和肌肉放松以及保健按摩等, 以 消除疲劳, 避免损伤身体。

\section{2 “实用” 是职业实用性体育教学模式构 建的核心}

构建实用性体育教育模式必须注重实 用性, 实用性原则是职业实用性体育教学模 
式构建的核心与命脉。职业实用性体育教学 模式要求教师教授与学生选择的体育运动 项目应该学生将来可能从事的工作具有很 大的关联系, 不仅仅是停留在通用能力的层 次之上。例如计算机信息专业的学生应该开 设一些有关武术、球类等实用性体育项目, 以达到训练学生上肢、肩带的静力性能力的 目的; 会计与财务管理专业的学生应该开设 一些有关握力、球类等实用性体育项目, 以 达到训练学生手指反应速度、公关礼仪的目 的; 旅游与酒店管理专业的学生应该开设一 些有关体育舞蹈、形体等实用性体育项目, 以达到训练学生有氧耐力和公关礼仪的目 的等等。

\section{3 “补偿” 是职业实用性体育教学模式 构建的要义}

“补偿”可以说是对“实用”的“补偿”, 它是构建实用性体育教育模式的应有之义, 是 “实用” 能够得以 “维护与持续” 的不竭 之源。补偿性原则是指参照惯例, 依据相同 或相似职业可能对其从事职业劳动的群体 的身体产生同样不良影响的后果, 因而需要 积极开设具有预防功效、矫正功效与保健功 效体育教学内容的原则。例如文秘、师范和 财会等具有 “伏案” 特征的行业, 因为静坐 的时间偏长, 且要求垂头含胸, 所以往往会 影响体形美, 甚至出现心肺功能降低等问 题, 对于从事这些行业的劳动者来说, 就需 要加强跑步、健美等体育项目的训练, 以提 高心肺功能, 矫正形体。

\section{4. “终身” 是职业实用性体育教学模式构 建的旨归}

学生毕竟要走出校园, 成为社会的一份 子。因此, 高职院校选择职业实用性体育教 学项目的内容不应该园直于校园之内, 更不 该仅仅限于工作岗位, 应该放眼未来, 着眼 学生的 “终身”, 使其成为学生终身锻炼的 一种方式, 一种习惯。将终身性原则作为高 职院校职业实用性体育教学模式的旨归, 就 是意在强调职业实用性体育教学模不是一 朝一夕的短暂性行为, 它应该伴随学生很长 一段时间, 乃至终身。所以对学生在选择进 行体育项目时, 也提出了一定的要求, 即除
了应该让学生考虑自己未来可能从事的职 业之外, 还应该考虑其自身的体征、兴趣和 爱好等诸多个性因素。

\section{4. 职业实用性体育教学模式的实践探索}

在研究了职业实用性体育教学模式构 建的原则之后。我们计划从课程体系、开设 内容、授课方式与评价方式等四个方面, 对 职业实用性体育教学模式进行总结与探索。

\section{1 课程体系: 课内和课外融为一体}

从课程体系来看, 职业实用性体育教学 模式要求实现课内课外融为一体。课外体育 教学是课内体育教学的有机延伸和必要补 充。《全国普通高等职业 (专科) 院校公共 体育课程教学指导纲要》(试行) 明确指出: “为实现体育课程目标, 应使课堂教学与课 外、校外的体育活动有机结合, 学校与社会 紧密联系。要把有目的、有计划、有组织的 课外体育锻炼、校外（社会、野外）活动、 运动训练等纳入体育课程, 形成课内外、校 内外有机联系的课程结构。”加强高职院校 职业实用性体育教学课内课外一体化建设, 需要进一步完善课程教学体系, 充分整合相 关资源, 使其各得其所, 形成 “三驾马车” 的有机统一。在课内应该重点传授职业实用 性体育的 “必需” 知识, 加强运动的基本技 能、方法以及意识的培养。在校内课外活动 中, 应该侧重学生职业实用性体育的兴趣、 爱好与个性的培养, 校外活动则 “应注重对 社会适应能力和各种社会活动的体验, 加 强团队意识和互助协作精神的培养, 从而深 化学生对人与自然人与社会、人与人关系 的理解。

\section{2 开设内容: “ $1+X$ ” 多元化选择}

从开设的课程内容来看, 职业实用性体 育教学模式要求实现 “ $1+X$ ” 的多元选择。

“ $1+X$ ” 多元化的选择即必须课程+专项课程 的内容开设方式。“ “ ” 是指面向所有专业 开设的必修课程。这主要是针对高职院校一 年级的学生开设的, 重点在于全面发展学生 的身体素质, 使学生形成健康的心理品质和 
健全的人格, 具备竞争意识与团队合作能 力, 达到《国家学生体质健康标准》。“X” 即针对不同专业不同人群开设的专项课程, 它主要是面向二年级与三年级等高年级开 设的。这就要求体育教师广泛深入企业一 线, 参照职业资格标准和相关行业企业一 起，共同制定标准，开发专项课程。

\section{3 授课方式: 游戏与学习合二为一}

从授课的方式来看, 职业实用性体育教 学模式要求实现游戏与学习合二为一。随着 体育教学改革不断深入以及大众体育的兴 起, 体育游戏越发引起人们的关注。实施职 业实用性体育教学要积极探索多种授课方 式, 注重将游戏引入课堂, 增强教学本身的 趣味性与娱乐性。实施职业实用性体育教学 模式应该注意以下几点: 第一, 注重将体育 与职业素养相融合, 不能 “成为教师应付课 程剩余时间的手段或有时教师为了达到活 跃课堂气氛的目的, 将一些与教学内容无关 的体育游戏生搬硬套到体育教学当中” ${ }^{[6]}$ 。 第二, 游戏的选择要与学生专业的发展相一 致, 不同的专业应该根据学生的专业特点选 用不同的游戏项目, 不能千篇一律, 如果所 有专业都采用都同样的游戏进行教学, 是达 不到教学目的的。第三, 注重创新性。开展 游戏的目的是为了引起学生的兴趣, 但由于 有的游戏学生已经 “玩淢” 了, 如果继续重 复使用, 这样不但提高不了学生的兴趣, 还 会产生逆反心理, 倦怠情绪。因此, 积极进 行游戏创新也是职业实用性体育教学迫切 需要解决的问题之一。

\section{4 评价方式: 动态综合考察相结合}

从开设的评价方式来看, 职业实用性体 育教学模式要求实现动态与综合考察相结 合。“动态” 考察即实施阶段性考核, 不再 以学生的单次成绩作为结课考核结果的考 核方式, 其目的在于分析差距, 找出问题与 不足, 修正下一个阶段的教学目标与任务, 更好的达到总体目标。职业实用性体育教学 模式的评价还要注重综合性考察。“综合性 考察” 即将平时表现、阶段测试与期末考核 等相结合。如游泳课程的考核平时表现可以
占据 $10 \%$, 阶段测试为 $60 \%$, 期末考核仅为 $30 \%$ 。

\section{5. 结束语}

构建职业实用性体育教学模式, 必须坚 守健康原则, 实用性原则、补偿性原则与终 身性原则, 着眼于课程体系、开设内容、授 课方式和评价方式等四方面。同时, 还应该 注意建职业实用性体育教学模式的完善与 成熟, 绝对不是一朝一夕的事情, 也不是一 个人一所学校能完成的, 它可能需要相当一 段时间, 许多人, 许多院校的共同努力。

\section{致谢}

本文为 2014 年度河北省人力资源与社 会保障厅研究课题:《高职院校体育教师“两 高一新” 人才培养模式研究》阶段性成果。

\section{References}

[1] Jun Zun. A Probe into the Practical Physi-cal Teaching in Higher Vocational Institutes,Journal of Tongren University, Vol.5, pp.140, 2014.

[2] Jiuxian $\mathrm{Gu}$, Yue Li.Under Horizon "servi-ce Taihu Lake Economic Circle" Pessional Practicality in Higher Vocational Colleges Necessity of Physical Education, Boshuo Fo-rum, Vol.4, pp.57, 2012.

[3] Xuelian Dong. The necessity of vocational practical P. E. teaching mode in higher voca-tional colleges, Health education, Vol.5,pp.258,2013.

[4] Menghua QIANG, Qi LING. Construction and implementation of vocational practical P. E. teaching mode in higher vocational colle-ges.Journal of S po rts A dult Education, Vo-1.3,pp.87,2010.

[5] Yong Chen. Research into the Practical PE Teaching in Vocational Colleges.Journal of Jiaxing University,vol.22, pp.141, 2010.

[6] Wei Qi. On the Application of Physical Education in Higher Colleges Sports Games. School of Physical Education vol.5,pp.129,2015. 